\title{
UNTANGLING FRENCH VOTING BEHAVIOR: Pierce Replies to Rosenthal
}

\section{Roy Pierce}

Rosenthal (1981) gets off to a bad start. The first sentence says "Pierce (1981) claims to have tested the Rosenthal-Sen $(1973,1977)$ spatial model of French voting behavior by using individual survey responses" (p. 363). Readers will look in vain for any such claim in my article. What $I$ did, "by a different method than that employed by Rosenthal and Sen" (Pierce, 1981 , p. 118), was to apply the same basic theory from which the Rosenthal-Sen spatial model was derived; the Davis, Hinich, and Ordeshook (1970) concept of the relationship between alienation and electoral participation.

I presented evidence in support of three propositions: (1) Participation at the second ballot in France in forced-choice situations can be accounted for by partisan attitudes (as measured by thermometer scores) but not by perceptions of partisan locations on the Left-Right dimension; (2) the partisan choices of the voters in such situations can be better explained by partisan attitudes than by Left-Right perceptions; and (3) deliberate abstainers in such situations resemble ballot spoilers, while chronic abstention and random abstention are long-term phenomena.

1. The first of these propositions is the most important, both substantively and in relation to the Rosenthal-Sen spatial model (1973). That model accounted for spoiled ballots (as opposed to participation) at the second round of voting in France in terms of distances between the available parties and the voter both when measures of partisan attitudes and Left-Right locations were employed as indicators of the distances involved. In other words, the Rosenthal-Sen (1973) work implied that Left-Right perceptions were as powerful a determinant of electoral participation as partisanship was.

Now, I do not doubt Rosenthal for a moment when he writes that "Sen and I were mainly interested in testing the spatial approach, not in arguing for the Left-Right dimension" (1981, p. 368). But while I too had a

Roy Pierce, Center for Political Studies, University of Michigan. 
methodological interest in spatial analysis, I also had a major substantive interest in the role of the Left-Right dimension as a determinant of electoral behavior. I was, therefore, not content simply to report that my findings differed from those of Rosenthal and Sen (1973). Instead, I also sought to show why the Rosenthal-Sen model "worked" with Left-Right perceptions when, according to my independent analysis, it should not have done so.

I concluded that the answer lay in two restrictions imposed on Rosenthal and Sen by their use of aggregate data. When I incorporated those two restrictions into my own analysis, it too worked with Left-Right perceptions as indicators of distance, suggesting strongly that those restrictions jointly accounted for why the Rosenthal-Sen (1973) analysis also worked under the same restrictions. But those constraints badly distort any effort to get at the determinants of individual electoral behavior for two familiar reasons: the impossibility of partitioning aggregate data to include only those people whose behavior is to be "explained" and the impossibility of employing exact individual-level measures.

In his reply to my article, Rosenthal (1981) makes no effort to refute my arguments concerning the effects of the use of aggregate data. Instead, he makes the curious and ultimately self-defeating argument that I erred because I did not take into account that in some cases the Rosenthal-Sen model "predicts the average distance to the closest candidate will be greater for voters than for spoilers" (1981, pp. 365-66). That is a strange point on which to insist. It should be obvious that it must remain an exception limited to comparatively few voters or the whole underlying theoretical notion that alienation can be expressed in terms of distance between voters and parties crashes to the ground.

Moreover, in explaining "this key point" (p. 363), Rosenthal demonstrates the extremely limited sense in which the Rosenthal-Sen alienation model can "predict" anything. It cannot go into effect until the electoral results are in. That is because the probability of any voter spoiling his or her ballot depends on a term, which Rosenthal calls "spatial location" (1981, p. 365), that is the product of the distance between the voter and the nearest available candidate times a coefficient, which he denotes as gamma, that varies from election to election and from party to party. Gamma, it turns out, is an atheoretical term that must be estimated for each party on the basis of the electoral returns for the year to which it applies.

Lastly, inspection of the table of estimates of gamma that Rosenthal and Sen present for the various parties in 1967 and 1968 (1973, Table 10) indicates that there is reason to doubt just how "spatial" their spatial model really is. Rosenthal illustrates his argument that the average distance to the closest candidate may be greater for voters than for spoilers with the case 
of the third district of the department of Lot-et-Garonne in 1967. However, on Rosenthal and Sen's own figures, the result of that same situation in 1968 would have been just the reverse of what he claims it was in 1967. The crucial aspect of the Lot-et-Garonne example that Rosenthal employs is that in 1967 the gamma for the Communists is less than half that for the Right; in 1968 it is nearly double that of the Right. It is difficult to understand in what sense these differing probabilities of nonvoting rest on "spatial locations" for-in the Rosenthal-Sen analysis-the Left-Right location of any given party was the same in 1968 as it had been in 1967. Party locations did not change from one year to the next; the empirically established gammas changed, and for unknown reasons that the guiding theory does not even purport to address.

2. With regard to explaining partisan choice, my conclusion was stated this way: “. . . perceptions of left-right distances do not account for participation, but once the voter has decided to cast a valid ballot, they account for his partisan choice, although not quite as well as partisan preferences do" (Pierce, 1981, p. 132). The evidence for this was a multiple regression, which produced a partial correlation coefficient of $r=.36$ for net advantage in partisan sympathy compared with a partial correlation of $r=.29$ for net advantage in Left-Right distance. Rosenthal objects to my conclusion on the grounds that regression would be an inappropriate statistical model if the dependent variable were dichotomous, and the difference between .36 and .29 is only .07 .

The dependent variable is dichotomous, and ordinary least-squares regression would be inappropriate if the dependent variable were badly skewed. Indeed, we did not rely on multiple regression to account for participation at the second ballot precisely because the participants so greatly outnumber the nonparticipants. But the mean on our dependent variable for partisan choice (which was scored 0,1 ) is .65 , which is within the acceptable range.

It is true that the difference between .36 and .29 is not large, but I do not think that my conclusion on this score, quoted above, makes any exaggerated claim. However, it should be noted that the appropriate comparison is between the two correlation coefficients squared, and that on that basis the larger score is some $50 \%$ larger than the smaller one.

3. Rosenthal's objection to my effort to distinguish deliberate abstainers from random and chronic abstainers and to show that the deliberate abstainers resemble the people who spoil their ballots rests mainly on the small number of cases available (to which I naturally called attention) and, it appears, a suspicion that $I$ had some ulterior motive in reporting only weighted $N s$ in my Table 2 while I reported unweighted $N s$ elsewhere.

Here is Rosenthal at work with regard to the number of cases: "Plunging ahead, however, one finds that Pierce has uncovered a grand total of nine 
deliberate abstainers in Table 3. This represents less than one-half of 1 percent of his sample, whereas second-ballot abstentions were 23.2 percent of the voting population" $(1981$, p. 367). I find it hard to believe that Rosenthal could not figure out that my deliberate abstainers represented some $4 \%$ of the subset of voters with which I was working (those unable to repeat their first-ballot partisan choice at the second ballot) and that the total number of my abstainers, to be compared with the $23.2 \%$ he cites, was some $11 \%$ of the subset with which I was working.

Now $11 \%$ is still far removed from $23 \%$, but just as aggregate data have their weaknesses so do survey data, and one of the latter's weaknesses is overreporting of electoral participation. However, while the underreporting of abstentions naturally affects case numbers adversely, there is little or no reason to think that the politically relevant attributes of the nonresponding abstainers are different from those reported by the respondents who acknowledge that they have abstained. That, plus the satisfactory levels of significance that I reported (which Rosenthal ignores), go a long way toward upholding my quite simple and theoretically sound notions that there is more than one kind of abstainer and that deliberate abstainers resemble ballot spoilers.

As for Table 2, I reported only the weighted $N$ s in order to save money. I originally ran the table with weighted data and did not rerun it unweighted because there was no technical need to do so. Where actual case numbers are important, I of course reported them unweighted. A rerun of Table 2 shows that while the weighted Ns reported in the two columns of that table are 49.5 and 28.0 , the unweighted $N$ s are 48 and 27 respectively.

\section{REFERENCES}

Davis, Otto A., Melvin J. Hinich, and Peter C. Ordeshook (1970). "An Expository Development of a Mathematical Model of the Electoral Process." American Political Science Review 64:426-448.

Pierce, Roy (1981). "Left-Right Perceptions, Partisan Preferences, Electoral Participation, and Partisan Choice in France." Political Behavior 3:117-136.

Rosenthal, Howard (1981). "Untangling French Voting Behavior: Tales of Aggregation." Political Behavior 3:363-369.

Rosenthal, Howard, and Subrata Sen (1973). "Electoral Participation in the French Fifth Republic." American Political Science Review 67:29-54.

Rosenthal, Howard, and Subrata Sen (1977). "Spatial Voting Models for the French Fifth Republic." American Political Science Review 71:1447-1466. 